\title{
Perubahan Fungsi Kognitif Peserta Program Pendidikan Dokter Spesialis (PPDS) Anestesiologi dan Terapi Intensif Fakultas Kedokteran Universitas Padjadjaran Setelah 24 Jam Kerja
}

\author{
Ati Nurchaeni Nurchaeni, Doddy Tavianto, Ezra Oktaliansah \\ Departemen Anestesiologi \& Terapi Intensif Fakultas Kdokteran Universitas Padjadjaran-RSUP. Dr. Hasan \\ Sadikin Bandung
}

\begin{abstract}
Abstrak
Latar Belakang dan Tujuan: Profesi dokter anestesi merupakan profesi dengan beban kerja tinggi yang dituntut untuk berpikir dan bertindak cepat dan tepat dalam situasi kritis. Kekurangan tidur, kelelahan, dan perubahan irama sirkadian mempengaruhi fungsi kognitif dokter anestesi. Tujuan penelitian ini untuk mengetahui perubahan fungsi kognitif peserta Peserta Program Pendidikan Dokter Spesialis (PPDS) Anestesiologi dan Terapi Intensif Fakultas Kedokteran Universitas Padjadjaran setelah 24 jam kerja yang diperiksa menggunakan Montreal Cognitive Assessment versi Indonesia (MoCA-INA).

Subjek dan Metode: Penelitian ini merupakan penelitian deskriptif observasional prospektif dengan pendekatan cross sectional yang dilakukan pada 62 subjek dengan memeriksa MoCA-INA jam ke-0 dan jam ke-24.

Hasil: Pada penelitian ini didapatkan penurunan nilai rata-rata MoCA-INA dengan nilai jam ke-0 yaitu 29,84 \pm 0,365 dan jam ke-24 yaitu 28,92 $\pm 1,010$. Berdasarkan aspek kognitif yang diperiksa, fungsi atensi merupakan aspek yang mengalami penurunan setelah jam ke-24. Penurunan nilai MoCA-INA paling banyak terdapat pada subjek yang bertugas di kamar operasi. Penurunan nilai rata-rata MoCA-INA setelah 24 jam kerja tersebut masih dalam batas normal karena masih di atas nilai acuan dan secara klinis tidak menunjukkan gangguan.

Simpulan: Terdapat penurunan fungsi kognitif peserta PPDS Anestesiologi dan Terapi Intensif Fakultas Kedokteran Universitas Padjadjaran setelah 24 jam kerja.
\end{abstract}

Kata kunci: anestesi; atensi; fungsi kognitif; kelelahan; montreal cognitive assessment versi Indonesia

JNI 2019; 8 (3): 160-67

\section{Cognitive Function Alterations on Residents Anesthesiology and Intensive Care of Medical Faculty Universitas Padjadjaran after 24 Hours Shift}

\begin{abstract}
Background and Objective: Anesthesiologist is a profession with a heavy workload which is need fast thinking and rapid decision making in a critical and life-threatening situation. Sleep deprivation, extended workshifts, exhaustion and circardian cycle changes can affect anesthesiologist's cognitive function. This aim of this study was to evaluate cognitive function changes in Residents of Anesthesiology and Intensive Therapy in Medical Faculty Universitas Padjadjaran after 24 hours shift using Montreal Cognitive Assesment-Indonesia Version (MoCA-INA). Subject and Method: This study was an observational-descriptive-prospective study using crosss sectional approach evaluating MoCA-INA score in 0th hour and 24th hour after shift in 62 subjects.

Result: The result of this study shown an average MoCA-INA score at 0th hour was $29.84 \pm 0.365$ while at 24th hours the average score was 28.92 \pm 1.010 . According to MoCA-INA, attention is the deprived domain at 24th hour after shift. MoCA-INA score declines mostly in subjects working in the operating room. According to MoCA-INA cut off value, the score of 26 is considered normal after 24 hours shift and not showing any clinical disturbance. Conclusion: The conclusion of this study is decreasing cognitive function among Anesthesiology Medical Faculty Universitas Padjadjaran residents after 24 hours shift.
\end{abstract}

Key words: anesthesiologists; attention; cognitive function; fatigue; montreal cognitive assessment Indonesian version

JNI 2019; 8 (3): 160-67 


\section{Pendahuluan}

Kelelahan adalah penurunan kondisi fisik atau mental setelah pengerahan tenaga atau pikiran dalam jangka waktu lama dan intens. Kelelahan juga timbul setelah melakukan kegiatan yang bersifat monoton dan kurang tantangan yang berakibat pada penurunan kapasitas dalam bekerja dan penurunan pencapaian. Kelelahan pada pekerja medis berhubungan dengan penurunan atensi dan orientasi yang merupakan salah satu aspek fungsi kognitif. Kondisi tersebut dapat memicu medication errors yang dapat berakibat fatal pada tatalaksana pasien. ${ }^{1}$ Dokter anestesi merupakan profesi yang lebih sensitif terhadap efek dari kelelahan dibanding dengan sejawat bidang lain dikarenakan dokter anestesi dituntut untuk selalu waspada. Tidur yang tidak teratur dan gangguan irama sirkadian selama jam kerja malam hari (nightshift) merupakan penyebab utama kelelahan pada dokter anestesi yang berakibat pada penurunan performa kognitif. Penelitian lain menyebutkan bahwa kekurangan tidur dapat mengubah struktur dan fungsional otak pada bagian tertentu sehingga berdampak pada perubahan fungsi kognitif. Faktor-faktor yang memengaruhi performa kognitif dokter anestesi diantaranya kelelahan baik fisik maupun mental, gangguan kualitas dan kuantitas tidur. ${ }^{1,2}$

Dokter anestesi adalah dokter penyedia pelayanan medis kepada pasien yang tidak hanya berperan di dalam kamar operasi untuk memberikan pelayanan perioperatif dalam pembedahan, namun berperan besar juga memberikan pelayanan medis di luar kamar operasi seperti kegawatdaruratan, manajemen nyeri, dan perawatan intensif. Anestesi merupakan salah satu pekerjaan dengan risiko tinggi dan stressful karena memiliki jam kerja yang panjang, membutuhkan hubungan interpersonal yang kuat, kewaspadaan tinggi, kompetensi yang baik, kemampuan psikomotor yang baik, tekanan pekerjaan yang tidak dapat diperkirakan, serta dituntut memiliki kemampuan mengambil keputusan yang cepat dan tepat. ${ }^{3,4}$ Penelitian yang dilakukan pada 20 peserta Program Pendidikan Dokter Spesialis (PPDS) Anestesiologi di Perancis yang diberikan simulasi manajamen bencana setelah jaga malam menunjukkan bahwa kekurangan tidur berhubungan dengan penurunan kewaspadaan, pengambilan keputusan, dan kerjasama tim. ${ }^{5}$ Penelitian fungsi kognitif yang dilakukan pada 51 dokter di Intensive Care Unit (ICU) di Perancis yang diperiksa dengan Wechsler Adult Intelligence Scale dan Wisconsin Card Sorting Test menunjukkan kemampuan kognitif dokter ICU menurun secara signifikan setelah 12 jam terjaga di malam hari. ${ }^{6}$ Penelitian fungsi kognitif yang dilakukan pada 97 perawat di India menggunakan MoCA setelah jaga malam menunjukkan penurunan yang signifikan. ${ }^{7}$

Setelah terjaga dalam waktu 17 hingga 19 jam dalam sehari, performa kognitif akan turun. Kondisi tersebut sebanding dengan seseorang yang mabuk dengan $0,05 \%$ konsentrasi alkohol dalam darah. Penurunan fungsi kognitif dokter anestesi karena kelelahan dan kekurangan tidur setelah bertugas penting untuk diketahui karena bisa berakibat fatal dalam tatalaksana pasien. Kejadian yang dilaporkan di Amerika Serikat menyebutkan seorang anak 8 tahun meninggal setelah kegagalan pemasangan pipa endotrakheal disebabkan dokter anestesi tersebut merasa lelah dan mengantuk sehingga tidak mampu melakukan tatalaksana komplikasi dari kegagalan pemasangan pipa endotrakheal. Dalam tindakan anestesia obstetrik, disebutkan pula bahwa dokter anestesi yang lelah dan mengantuk memiliki risiko 6 kali lebih besar untuk melakukan dural puncture ketika melakukan tindakan epidural.

Selain MoCA, penapisan pemeriksaan fungsi kognitif secara global dapat dilakukan dengan instrumen mini-mental state examination (MMSE), clock drawing test (CDT), general practicioner assessment of cognition (GPCOG), Saint Louis University Mental Status (SLUMS). Instrumen MoCA dipilih untuk pemeriksaan fungsi kognitif pada penelitian ini dikarenakan berdasarkan uji sensitivitas, MoCA memiliki nilai tertinggi hingga $100 \%$ dibandingkan instrumen yang lain. ${ }^{8,9}$ Sampai saat ini belum ada data mengenai perubahan fungsi kognitif peserta PPDS Anestesiologi dan Terapi Intensif Fakultas Kedokteran Universitas Padjadjaran setelah 24 jam kerja sehingga perlu dilakukan penelitian tentang hal tersebut. Penelitian ini bertujuan 
untuk mengetahui perubahan fungsi kognitif peserta PPDS Anestesiologi dan Terapi Intensif Fakultas Kedokteran Universitas Padjadjaran setelah 24 jam kerja.

\section{Subjek dan Metode}

Penelitian ini bersifat deskriptif dengan pengambilan data menggunakan instrumen MoCA-INA. Penelitian dilakukan di RSUP Dr. Hasan Sadikin Jalan Pasteur 38 Bandung pada bulan Maret sampai dengan April 2018. Subjek penelitian adalah seluruh peserta PPDS Anestesiologi dan Terapi Intensif Fakultas Kedokteran Universitas Padjadjaran yang masih aktif hingga tahun 2018. Kriteria inklusi meliputi peserta PPDS yang memberikan pelayanan $24 \mathrm{jam}$ di lingkungan RSUP Dr. Hasan Sadikin Bandung. Kriteria eksklusi yaitu peserta PPDS yang tidak berkenan ikut dalam penelitian, bertugas $2 \times 24$ jam berturut-turut, mengkonsumsi obat tidur, obat anti cemas atau anti depresi dalam kurun waktu 24 jam sebelum, selama dan setelah bekerja 24 jam, tidak mengikuti penelitian hingga selesai. Ukuran sampel untuk penelitian ini menggunakan rumus Slovin dan didapatkan jumlah sampel minimal 57 orang. Pemilihan sampel secara nonprobabilitas dengan teknik purposive sampling. Data hasil penelitian dianalisis kemudian dideskripsikan menggunakan tabel sesuai dengan variabel yang diidentifikasi.

Penelitian dimulai setelah mendapatkan ijin dari Komite Etik Penelitian Kesehatan Fakultas Kedokteran Universitas Padjadjaran/Rumah Sakit Dr. Hasan Sadikin Bandung. Pemeriksaan kognitif dilakukan kepada peserta PPDS yang bertugas di kamar operasi Instalasi Gawat Darurat (IGD), High Care Unit (HCU), Intensive Care Unit (ICU), dan ruang resusitasi. Pemeriksaan dilakukan 2 kali yaitu pada waktu sebelum jaga pukul 06.00 dan setelah jaga pukul 06.00 keesokan harinya. Instrumen MoCA sudah diterjemahkan, diadaptasi, melewati uji validitas dan reliabilitas di Fakultas Kedokteran Universitas Indonesia sehingga dapat digunakan di Indonesia menjadi MoCA-INA. Instrumen MoCA-INA terdiri dari 13 pertanyaan yang mencakup 7 aspek fungsi kognitif yang diperiksa meliputi visuospasial eksekutif, penamaan, atensi, bahasa, abstraksi, memori tunda, dan orientasi. Nilai untuk jawaban dari aspek visuospasial eksekutif diberi skala 0 sampai 5 , aspek penamaan diberi skala 0 hingga 3 , aspek atensi diberi skala 0 sampai 6 , aspek bahasa diberi skala 0 sampai 3 , aspek abstraksi diberi skala 0 hingga 2 , aspek memori tunda diberi skala 0 hingga 5, dan aspek orientasi diberi skala 0 hingga 6 . Hasil pemeriksaan MoCA-INA memiliki jumlah nilai maksimal 30. Nilai acuan gangguan fungsi kognitif pada $\mathrm{MoCA}$ adalah 26. Setelah dilakukan pemeriksaan, nilai hasil pemeriksaan MoCA-INA diolah melalui program Statistical Product and Service Solutions (SPSS) versi 24.0 for Windows.

\section{Hasil}

Jumlah peserta PPDS Anestesiologi dan Terapi Intensif di RSUP Dr. Hasan Sadikin yang mengikuti penelitian sebanyak 62 orang $(68,8 \%$ dari jumlah PPDS Anestesiologi dan Terapi Intensif RSUP Dr. Hasan Sadikin Bandung). Berdasarkan jenis kelamin, 40 orang $(64,5 \%)$ adalah laki-laki, sedangkan 22 orang $(35,4 \%)$

Tabel 1. Karakteristik Subjek Penelitian

\begin{tabular}{lll}
\hline Variabel & $\mathrm{n}=62$ & $\begin{array}{l}\text { Persentasi } \\
(\%)\end{array}$ \\
\hline $\begin{array}{l}\text { Jenis kelamin } \\
\text { Laki-laki }\end{array}$ & 40 & $64,5 \%$ \\
Perempuan & 22 & $35,4 \%$ \\
Usia (tahun) & & \\
Mean \pm Std & $32,55 \pm 3,319$ & \\
Median & 33,00 & \\
Range & $26-40$ & \\
(min - max) & & \\
Lama tidur & & \\
sebelum jaga & & \\
(jam) & & \\
Mean \pm Std & $5,62 \pm 0,962$ & \\
Median & 6,00 & \\
Range (min - & $4-8$ \\
max) & & \\
\hline
\end{tabular}

Keterangan: Untuk data kategorik disajikan dengan jumlah/frekuensi dan persentase sedangkan data numerik disajikan dengan rerata, median, standar deviasi dan interquartile range 
Spesialis (PPDS) Anestesiologi dan Terapi Intensif Fakultas Kedokteran Universitas Padjadjaran Setelah 24 Jam Kerja

Tabel 2. Perbandingan Lama Tidur Sebelum dan Saat Jaga

\begin{tabular}{lll}
\hline Variabel & Sebelum Jaga & Saat Jaga \\
\hline IGD & & \\
Mean & $5,64 \pm 0,87$ & $0,47 \pm 0,78$ \\
Median & 6 & 0,00 \\
$\quad$ Range $(\min -\max )$ & $4-8$ & $0-3$ \\
HCU & & \\
Mean \pm Std & $6 \pm 1,00$ & $2,14 \pm 0,69$ \\
Median & 6,00 & 2,00 \\
Range $(\min -\max )$ & $5-8$ & $3-6$ \\
ICU & & \\
Mean \pm Std & $6,25 \pm 0,5$ & $1,12 \pm 0,62$ \\
Median & 6,00 & 1,00 \\
Range $(\min -\max )$ & $6-7$ & $0-2$ \\
Resus & & \\
Mean \pm Std & $5,16 \pm 1,19$ & $2,91 \pm 0,90$ \\
Median & 5 & 3,00 \\
Range $(\min -\max )$ & $4-8$ & $2-6$ \\
\hline
\end{tabular}

Keterangan: Untuk data kategorik disajikan dengan jumlah/frekuensi dan persentase sedangkan data numerik disajikan dengan rerata, median, standar deviasi dan interquartile range

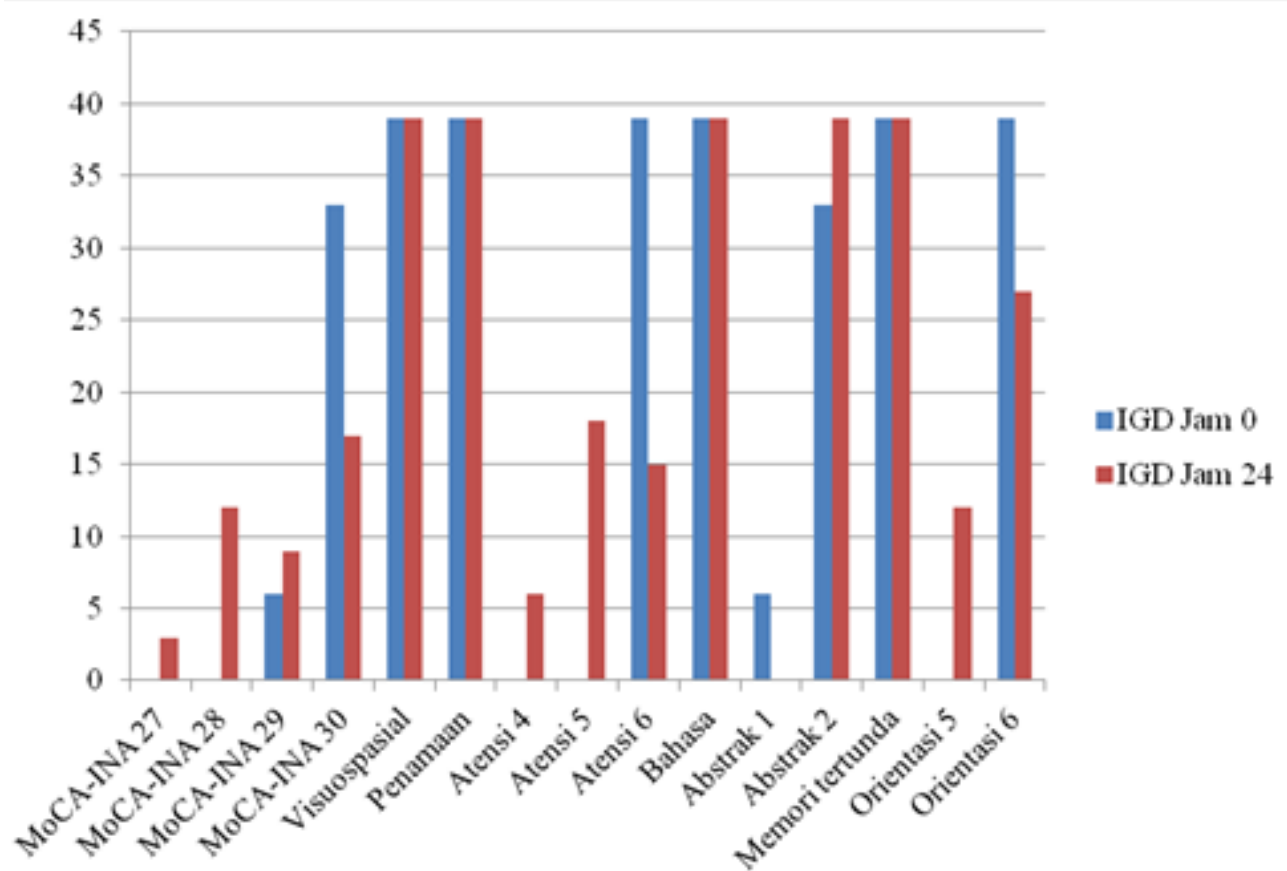

Grafik 1 Hasil Pemeriksaan Jam ke 0 dan Jam ke 24 pada Saat Jaga IGD

adalah perempuan. Berdasarkan umur, subjek penelitian memiliki rata-rata umur 33 tahun. Berdasarkan lama waktu tidur sebelum bertugas 24 jam, rata-rata peserta PPDS tidur selama 5,62 $\pm 0,962$ jam, dan berdasarkan lama tidur selama bertugas 24 jam, peserta PPDS yang bertugas di kamar operasi IGD rata-rata 0,47 jam, HCU $4,43 \pm 0,97$ jam, ICU 0,62 $\pm 0,48$ jam, dan ruang resusitasi 3,50 \pm 1.24 jam (Tabel 1).

Pada penelitian ini, nilai rata-rata MoCA- 


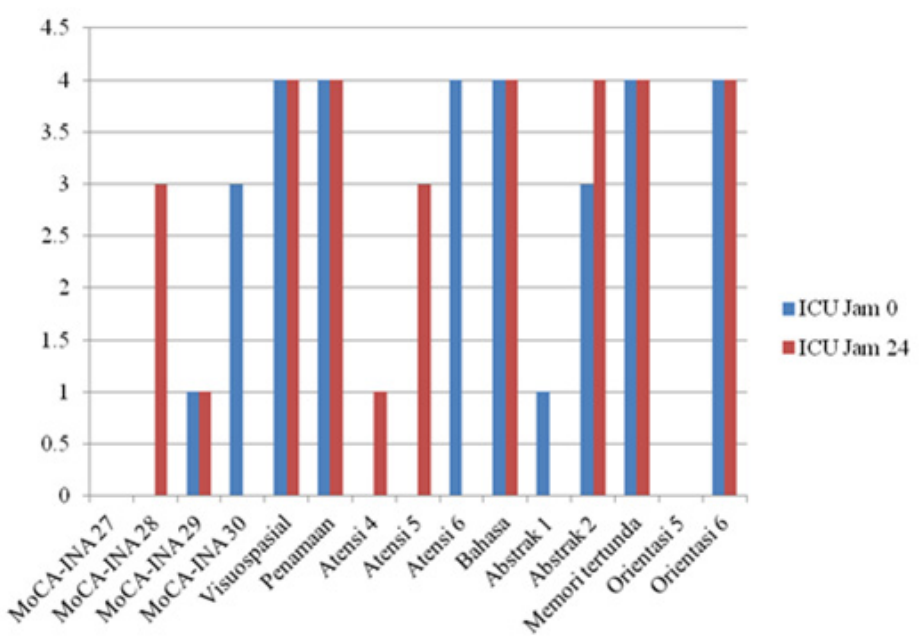

Grafik 2. Hasil Pemeriksaan Jam ke 0 dan Jam ke 24 pada saat Jaga ICU

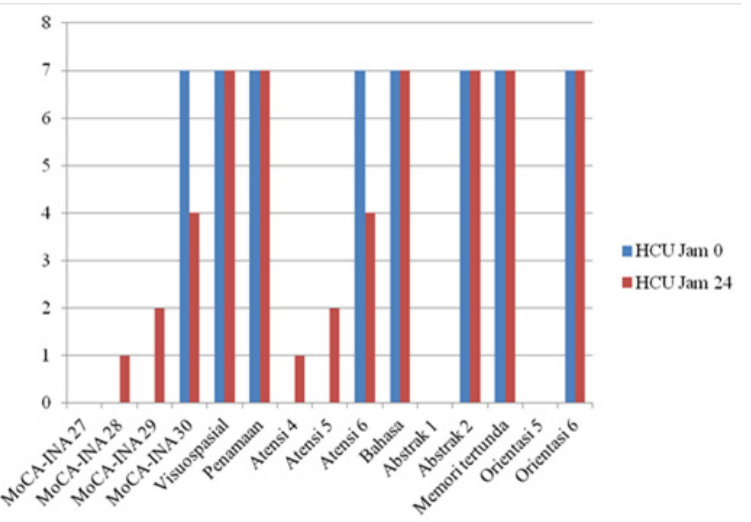

Grafik 3. Hasil Pemeriksaan Jam ke 0 dan Jam ke 24 pada saat Jaga $\mathrm{HCU}$

INA pada jam ke-0 untuk peserta PPDS yang melakukan pelayanan di kamar operasi IGD didapatkan hasil 29,84 $\pm 0,365$, HCU 30,00, ICU $29,75 \pm 0,500$, dan ruang resusitasi $29,75 \pm 0,452$. Hasil pemeriksaan aspek fungsi kognitif MoCAINA pada jam ke-0 untuk aspek visuospasial eksekutif, penamaan, atensi, bahasa, memori tunda, dan orientasi seluruh peserta mendapatkan nilai maksimal. Pada penelitian ini, nilai ratarata MoCA-INA pada jam ke-24 untuk peserta PPDS mengalami penurunan dibanding dengan nilai rata-rata MoCA-INA pada jam ke-0. Hasil pemeriksaan aspek fungsi kognitif visuospasial, penamaan, bahasa, dan memori tunda MoCAINA jam ke-24, seluruh peserta mendapatkan nilai maksimal. Hal yang menarik adalah terjadi penurunan untuk aspek atensi untuk peserta PPDS

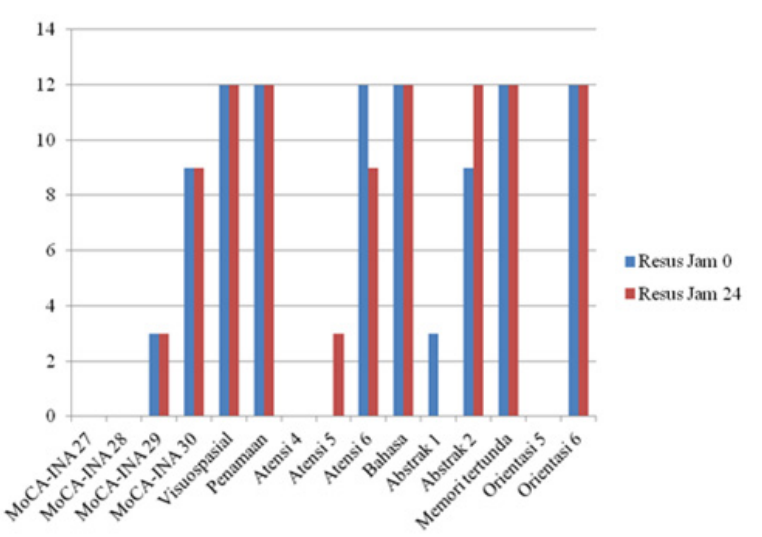

Grafik 4. Hasil Pemeriksaan Jam ke 0 dan Jam ke 24 pada saat Jaga Resus

yang bertugas di kamar operasi IGD dan ICU. Dari 39 peserta PPDS yang bertugas di kamar operasi IGD hanya 15 orang yang mendapat nilai maksimal 6 pada aspek atensi. Dari 4 peserta PPDS yang bertugas di ICU, tidak ada orang yang mendapat nilai maksimal 6 pada aspek atensi.

\section{Pembahasan}

Jumlah PPDS Anestesiologi dan Terapi Intensif yang mengikuti penelitian ini sebanyak 62 orang. Berdasarkan jenis kelamin, 40 orang lakilaki $(64,5 \%)$ dan 22 orang perempuan $(35,4 \%)$. Berdasarkan rentang usia, peserta penelitian memiliki rentang usia 26-40 tahun, dengan ratarata usia 33 tahun. Penelitian tentang data normatif hasil pemeriksaan MoCA pada populasi dewasa 
muda di Italia menyebutkan bahwa tidak ada pengaruh yang signifikan untuk perbedaan jenis kelamin terhadap hasil pemeriksaan MoCA. ${ }^{10}$ Penelitian tentang pengaruh sosiodemografi dan status kesehatan terhadap fungsi kognitif yang diperiksa dengan MoCA pada populasi dewasa muda di Portugal menyebutkan bahwa usia dan tingkat pendidikan memberikan pengaruh yang signifikan terhadap hasil pemeriksaan MoCA. Usia tua secara signifikan meningkatkan probabilitas hasil MoCA yang rendah. ${ }^{11}$ Penelitian ini tidak membedakan antara fungsi kognitif laki-laki dan perempuan. Hasil pemeriksaan MoCA-INA pada penelitian ini menunjukkan nilai di atas nilai acuan yaitu 26. Hal tersebut terjadi kemungkinan dikarenakan subjek penelitian merupakan usia dewasa muda dengan latar belakang pendidikan yang sama yaitu sarjana.

Rata-rata lama tidur malam sebelum memulai aktivitas 24 jam sebesar 5,62 $\pm 0,962$ jam. Sementara itu, rata-rata lama tidur selama 24 jam kerja bervariasi, untuk peserta PPDS yang bertugas di kamar operasi IGD rata-rata 0,47 jam, HCU 4,43 $\pm 0,97$ jam, ICU 0,62 $\pm 0,48$ jam, dan ruang resusitasi 3,50 $\pm 1,24$ jam. Kuantitas dan kualitas tidur berperan penting dalam fungsi kognitif. Secara kuantitas, normal lama tidur yang dibutuhkan dewasa muda sekitar 6-8 jam dalam sehari. Kualitas tidur dinilai sesaat, harian maupun bulanan menggunakan instrument polysomnography, Pittsburgh Sleep Quality Index (PSQI) atau Epworth Sleepiness Scale (ESS). ${ }^{12}$

Dalam penelitian ini, kuantitas tidur subjek penelitian sebelum aktivitas 24 jam dikategorikan normal, dengan rata-rata lama waktu tidur 6 jam. Namun, selama aktivitas 24 jam, rata-rata lama tidur subjek penelitian terutama di kamar operasi IGD dan ICU kurang dari 1 jam. Penelitian ini tidak melihat kualitas tidur dari subjek penelitian. Hasil pemeriksaan MoCA-INA setelah 24 jam kerja dengan lama tidur hanya 1 jam terdapat penurunan antara hasil MoCA-INA pada jam ke-0 dan jam ke-24 namun tetap menunjukkan hasil di atas nilai acuan 26 sehingga masih dalam kategori normal. Hasil penelitian ini sesuai dengan penelitian pengaruh kekurangan tidur terhadap peserta PPDS Anestesiologi di Kroasia setelah 24 jam kerja yang menunjukkan bahwa 24 jam kerja tidak memengaruhi keseluruhan fungsi kognitif, terutama untuk kegiatan yang membutuhkan atensi dan konsentrasi dengan jangka waktu pendek. ${ }^{13}$ Hasil pemeriksaan MoCA-INA setelah 24 jam kerja masih diatas nilai acuan kemungkinan dikarenakan karakteristik tidur peserta PPDS saat jaga malam yang sudah terpola untuk sedikit tidur bahkan tidak tidur dan terbiasa menahan kantuk dengan tetap kondisi waspada dalam melakukan tatalaksana terhadap pasien. Selain itu, kemungkinan karena pemeriksaan MoCA-INA ini sudah dilakukan sehari sebelumnya saat diperiksa jam ke-0, sehingga ketika diperiksa pada jam ke-24 subjek penelitian sudah mengetahui pertanyaan yang akan diberikan karena adanya learning effect. Selain nilai rata-rata MoCA-INA setelah jam ke24 yang menurun, yang menarik adalah jumlah subjek yang mencapai nilai maksimal MoCAINA setelah jam ke-24 juga menurun.

Berdasarkan pemeriksaan 7 aspek fungsi kognitif MoCA-INA pada penelitian ini, penurunan terjadi pada aspek atensi. Pemeriksaan fungsi atensi terhadap 39 peserta PPDS yang bertugas di kamar operasi pada jam ke-0, didapatkan seluruh subjek $(100,00 \%)$ mendapat nilai maksimal 6 . Sedangkan, pada jam ke-24 hanya 15 orang subjek (38.5\%) yang mendapat nilai maksimal 6 pada fungsi atensi, sedangkan sisanya mendapat nilai di bawah. Hampir setengah dari jumlah peserta PPDS yang bertugas di kamar operasi IGD tidak dapat mencapai nilai maksimal MoCA-INA setelah 24 jam kerja, sementara peserta PPDS yang bertugas di ICU sama sekali tidak ada yang dapat mencapai nilai maksimal setelah 24 jam kerja. Hasil pemeriksaan MoCA-INA peserta PPDS yang bertugas di kamar operasi IGD pada jam ke-0, didapatkan 33 orang subjek $(84,6 \%)$ mendapatkan nilai maksimal 30, dan 6 orang subjek $(15,4 \%)$ mendapatkan nilai 29 . Namun, setelah jam ke-24 hanya 15 orang $(38,5 \%)$ yang mendapat nilai maksimal 30 , sedangkan sisanya mendapatkan nilai di bawah 30. Hampir setengah dari jumlah peserta PPDS yang bertugas di kamar operasi IGD tidak dapat mencapai nilai maksimal pada fungsi atensi setelah 24 jam kerja. Fungsi atensi pada peserta PPDS yang bertugas 
di kamar operasi setelah jaga malam mengalami penurunan kemungkinan dikarenakan jumlah dan tingkat kesulitan pasien yang dikonsulkan dan dikerjakan di kamar operasi IGD bervariasi.

Hasil pemeriksaan MoCA-INA 4 peserta PPDS yang bertugas di ICU pada jam ke-0, didapatkan 3 orang subjek (75\%) mendapatkan nilai maksimal 30 , dan 1 orang subjek $(25 \%)$ mendapatkan nilai 29. Namun, setelah tidak ada peserta PPDS yang mendapat nilai maksimal 30 . Hasil penelitian ini sesuai dengan penelitian fungsi kognitif yang diperiksa dengan MoCA terhadap perawat di India setelah jaga malam menunjukkan hasil penurunan pencapaian hasil MoCA. ${ }^{7}$ Hal menyebabkan konsentrasi sebagian besar peserta PPDS sudah menurun saat diperiksa dikarenakan jumlah pasien yang ditangani banyak dan sulit sehingga berdampak pada jumlah lama tidur saat jaga dengan rata-rata lama tidur saat jaga di ICU hanya $0,62 \pm 0,48$ jam. Selain itu, penurunan aspek atensi terjadi pada peserta PPDS yang bertugas di ICU. Pemeriksaan fungsi atensi 4 peserta PPDS yang bertugas di ICU pada jam ke-0, didapatkan seluruh subjek $(100,00 \%)$ mendapat nilai maksimal 6 pada fungsi atensi. Sedangkan, pada jam ke-24 tidak ada peserta PPDS yang bertugas di ICU yang mendapat nilai maksimal 6 pada fungsi atensi. Selain itu peserta PPDS yang bertugas di ICU setelah jaga malam mengalami penurunan kemungkinan dikarenakan saat jaga ICU peserta PPDS hanya 1 orang dan harus menangani hingga 15 pasien yang berada di ICU dengan berbagai kompleksitas penyakit. Hasil penelitian ini sesuai dengan penelitian fungsi atensi dan memori yang dilakukan pada 40 peserta PPDS Penyakit Dalam di Brazil setelah jaga malam mengalami penurunan. ${ }^{14}$ Pusat fungsi kognitif individu secara anatomi berada pada korteks prefrontal. Korteks prefrontal paling sensitif terhadap paparan lelah dan kekurangan tidur. Kondisi lelah dan kekurangan tidur memicu terjadinya perubahan histologi, neurotransmiter dan proses neuroinflamasi di otak. Perubahan histologi yang terjadi pada korteks prefrontal berupa hilangnya material dendrit pada lapisan II dan III korteks prefrontal. Perubahan neurotransmiter yang timbul adalah peningkatan noradrenalin yang mudah menembus sawar darah otak dan berikatan dengan reseptor orexin di kortkes prefrontal yang berperan penting dalam atensi dan memori. Proses neuroinflamasi di otak pada kondisi lelah dan kekurangan tidur dipicu oleh sitokin tumor necrosis factor $\alpha(\mathrm{TNF} \alpha)$, interleukin-6 (IL-6), dan interleukin-8 (IL-8). ${ }^{15,16}$

PPDS yang bertugas di HCU aspek atensi tidak mengalami penurunan setelah 24 jam kerja. Hal ini dikarenakan peserta PPDS yang bertugas di HCU walaupun hanya 1 orang menangani 5 orang pasien. Perserta PPDS yang bertugas di ruang resusitasi, aspek atensi tidak mengalami penurunan setelah 24 jam kerja. Hal tersebut kemungkinan disebabkan karena di ruang resusitasi walaupun jumlah dan tingkat kesulitan pasien juga bervariasi, namun setelah kondisi gawat darurat tertangani di ruang resusitasi maka pasien selanjutnya dikembalikan ke bagian lain untuk tatalaksana selanjutnya.

\section{Simpulan}

Pada penelitian ini didapatkan hasil bahwa terdapat penurunan fungsi kognitif peserta PPDS Anestesiologi dan Terapi Intensif setelah 24 jam kerja yang diperiksa dengan instrumen MoCAINA. Penurunan aspek fungsi kognitif setelah 24 jam kerja terutama adalah aspek atensi. Perlunya penambahan jumlah peserta PPDS, pergantian personel setelah 24 jam kerja terutama untuk peserta PPDS yang bertugas di kamar operasi dan ICU, diadakan edukasi dan pelatihan mengenai sleep hygiene pada peserta PPDS.

\section{Daftar Pustaka}

1. Gregory $P$, Edsell M. Fatigue and the anaesthetist. Br J Anaesth. 2014;14(1):18-22.

2. Chandran R, DeSousa KA. Human factors in anaesthetic crisis. WJA 2014;3(3):203-12

3. Verma R, Mohan B, Attri JP, Chatrath V, Bala A, Singh M. Anesthesiologist: the silent force behind the scene. Anesth Essays Res. 2015;9:293-7. 
Spesialis (PPDS) Anestesiologi dan Terapi Intensif Fakultas

Kedokteran Universitas Padjadjaran Setelah 24 Jam Kerja

4. Rall M, Gaba DM, Howard SK, Dieckmann P. Human performance and patient safety. Dalam: Miller R, penyunting. Miller's Anesthesia Edisi Ke-7. Philadelphia: Elsevier; 2010: 113-21.

5. Daret SA, Buleon C, Bocca ML, Denise P, Gerard JL, Hanouz JL. Effect of sleep deprivation after a night shift duty on simulated crisis management by residents in anaesthesia. A randomised crossover study. Anaesth Crit Care Pain Med. 2017;37(2):161-6.

6. Maltese F, Adda M, Bablon A, Hraeich S, Guervilly C, Lehingue S, dkk. Night shift decreases cognitive performance of ICU physicians. Intensive Care Med J. 2015:2-9.

7. Kaliyaperumal D, Elango Y, Alagesan M, Santhanakrishanan I. Effects of sleep deprivation on the cognitive performance of nurses working in shift. J Clin Diagn Res. 2017;11(8):1-3.

8. Freddi Segai-Gidan PA. Cognitive screening tools. Clinician Reviews. 2013 Jan;23(1):12.

9. Husein $\mathrm{N}$, Lumempouw $\mathrm{S}$, Herqutanto YR. Uji validitas dan reliabilitas montreal cognitive assessment versi Indonesia untuk skrining gangguan kognitif. Neurona. 2010;27(4):2-8.

10. Santangelo G, Siciliano M, Pedone R, Vitale
C, Falco F, Bisogno R, dkk. Normative data for the montreal cognitive assessment in an Italian population sample. Neurol Sci. 2015;36:585-91.

11. Freitas S, Simoes MR, Alves L, Santana I. Montreal cognitive assessment influence of sociodemographic and health variables. Arch Clin Neuropsychol. 2012:165-75.

12. Landolt HP, Sousek A, Holst SC. Effects of acute and chronic sleep deprivation. J Sleep Res. 2014:1-14.

13. Tadinac M, Sekulic A, Hromatko I, Sunko BM, Ivancic R. Age and individual sleep characteristics affect cognitive performance in anesthesiology residents after 24-hour shift. Acta Clin Croat. 2014;53:22-30.

14. Suozzo AC, Malta SM, Gil G, Tintori F, Lacerda SS, Martins LAN. Attention and memory of medical residents after a night on call: a crosssectional study. Clinics. 2011;66(3):505-8.

15. Arnsten AFT. Stress signaling pathways that impair prefrontal cortex structure and function. Nat Rev Neurosci. 2009;10(6):410-22.

16. Goel N, Rao H, Durmer JS, Dinges DF. Neurocognitive cosequences of sleep deprivation. Semin Neurol. 2009; 29 (4): 320-39. 